\title{
'Everyday Bordering' in England, Sweden and Bulgaria: Social Work Decision-Making Processes When Working with Migrant Family Members
}

\author{
Julie Walsh $^{1} \cdot$ Evelyn $\mathrm{Khoo}^{2} \cdot$ Karina Nygren $^{3}$
}

Accepted: 19 April 2021/Published online: 21 May 2021

(C) The Author(s) 2021, corrected publication 2021

\begin{abstract}
The global movement of people is a growing feature of contemporary life, and it is essential that professionals providing support services know how to best engage with migrant families. However, despite globalisation and the related processes of debordering, borders continue to remain significant and, in contemporary life, the ways in which immigration is controlled and surveilled-bureaucratically and symbolically - are multiple. The paper draws on data gathered in the immediate period following the so called 2015 European 'migration crisis' and examines whether and in what ways social workers in three European countries-Bulgaria, Sweden and England - enact bordering in their work with migrant family members. We apply the concept of 'everyday bordering' to the data set: whilst borders are traditionally physical and at the boundary between nation states, bordering practices increasingly permeate everyday life in bureaucratic and symbolic forms. Overall, the data show that everyday bordering affects social work practice in three ways: by social workers being required to engage in bordering as an everyday practice; by producing conditions that require social workers to negotiate borders; and in revealing aspects of symbolic everyday bordering. Our analyses shows that 'everyday bordering' practices are present in social work decision-making processes in each country, but the forms they take vary across contexts. Analysis also indicates that, in each country, social workers recognise the ways in which immigration control can impact on the families with whom they work but that they can also inadvertently contribute to the 'othering' of migrant populations.
\end{abstract}

Keywords Everyday bordering $\cdot$ Social work $\cdot$ Family $\cdot$ Street-level bureaucracy

Julie Walsh

j.c.walsh@sheffield.ac.uk

1 Department of Sociological Studies, University of Sheffield, S102TU, Sheffield, UK

2 Department of Social Work, University of Gothenburg, 40530 Gothenburg, Sweden

3 Department of Social Work, University of Umeå, 90187 Umeå, Sweden 


\section{Introduction}

The global movement of people, for political, economic and environmental reasons, is a growing feature of contemporary life ${ }^{1}$. Despite globalisation and the related processes of de-bordering, borders remain significant. However, this is not just in terms of boundaries between nation states but also as internal policies and practices enacted by state and non-state actors (Parker and Adler-Nissen 2012). Scholars of migration studies argue, then, that whilst immigration control is traditionally perceived to be at external, concrete, national borders, in contemporary life, the ways in which immigration is controlled and surveilled - bureaucratically and symbolically-are multiple (Brambilla et al. 2015; Ozdemir and Ayata 2018; Peterson 2017; Cassidy et al. 2018). Researchers have, therefore, developed the concept of everyday bordering to describe how state bordering practices extend increasingly into everyday life (YuvalDavis et al. 2017; Yuval-Davis et al. 2019). It is this internal 'everyday border' construction, in the context of social work practice, that we consider in this paper.

Lipsky coined the term 'street-level bureaucracy' in 1969, to describe the relationship between state-level policymaking, the decision-making processes of public servants and the organisational context in which they operate (Lipsky 2010). Scholars have since developed Lipsky's concept and show that public servants exercise professional discretion when enacting policy at the 'street level' and navigating organisational mechanisms designed to control and direct their behaviour (Prottas 1978). Despite this, it remains that the decisions made by professionals are highly dependent on context, and for Molander (2016), they do determine 'who passes through the gates of the welfare state' (Molander 2016: 90). As such, those who support migrant families have to balance families' needs with state requirements related to internal immigration control. Social workers (SW), as one such group, are expected to engage effectively with, and support, migrant families with whom they work (including asylum seekers, refugees, economic migrants, international students from diverse cultural and ethnic backgrounds). Bordering practices can, however, intrude on everyday lives of migrants and produce hierarchies in and between people that are seen to be migrant, and those that are not, thereby reinforcing existing inequalities and outcomes for migrant families (Tervonen et al. 2018; Anthias 2021). The requirement to check a person's migration status to ascertain their 'right' to access a specific service is an example of such a practice. In the case of social work, we identify everyday bordering practices as those that regulate and constrain professional decision-making, grounded in implicit or explicit considerations of citizenship and belonging. This paper thereby provides a timely understanding of social work responses to migrant family members and uniquely applies the theoretical lens of everyday bordering (Yuval-Davis et al., 2017; YuvalDavis et al., 2019) to related decision-making processes.

A body of research considers how 'everyday borders' — or state expectations relating to immigration control-are enacted. This is limited to sectors such as housing (JCWI 2015) and higher education (Jenkins 2014) in the UK, and the impact of such practices on specific migrant populations, such as Romanians in Helsinki (Tervanon and Enache 2017). However, whilst professional practice with migrant populations is an expanding

\footnotetext{
${ }^{1}$ Migration is a highly contested concept. We use migration/migrant to refer to the movement of individuals or groups relative to one another regardless of the motivations (e.g. refuge or economic) for their movement.
} 
research field, existing literature relating to social work is often country-specific (Shier et al. 2011; Briscman and Dean, 2016) or considers work and outcomes with specific groups such as irregular migrants (Björngren Cuadra and Staaf 2014), asylum-seeking adults (Chantler 2012; Fell and Fell 2014) and unaccompanied asylum-seeking minors (Cemlyn and Nye 2012; Sundqvist et al. 2015). Subsequently, Cox and Geisen (2014) assert that comparing approaches to migration in different social and welfare contexts is an underdeveloped area of social work research. As such, this paper contributes by examining social work responses to migrant family members in Bulgaria, Sweden and England and considers whether, and in what ways, SWs from these countries enact or resist internal state bordering practices in their work with migrant family members.

\section{Everyday Bordering: Immigration Control and Prevalent Narratives in Sweden, England and Bulgaria}

Sweden, England and Bulgaria are of comparative interest in terms of migration for a number of reasons. In 2018, the UK and Sweden were net receivers of migration, with respective net migration of 198,000 and 50,792. By contrast, Bulgaria had a negative net migration figure of $-4,894$ (Statista 2018). Whilst figures fluctuate, these countries have maintained their positive and negative migration figures for some years. Further, the data on which this paper draws was gathered in the period immediately following the, so called, 2015 European migration crisis ${ }^{2}$. Whilst Bulgarian history is characterised by emigration, it has long been a transit country for people that enter Europe via Greece and Turkey and are en route to the Schengen area ${ }^{3}$ and wealthier countries in north and west Europe, where they hope to seek refuge. After 2011, and the start of the war in Syria, there was, however, a substantial increase in the number of people using this route to flee conflict in their countries of origin and figures peaked in 2015 (Berry et al. 2015). Whilst Sweden is in the Schengen area, the UK has negotiated an opt-out clause with the EU and maintains heavy controls at physical borders. Consequently, during 2015, Sweden received 156,110 asylum applications (108\% increase), Bulgaria 20,165 (87\% increase) and the UK 38,370 (19\% increase) (Eurostat 2016). This led to varying levels of increased demands on the related social care systems.

Although all three countries examined - as EU members at the time of the studywere obliged to uphold EU immigration law, such as the Dublin Agreement ${ }^{4}$, they have different approaches to immigration management and everyday bordering practices. In England, in recent decades, media and policy narratives promoting immigration control have become increasingly prevalent (Greenslade 2005; Mulvey 2010), and this has

\footnotetext{
${ }^{2}$ Whilst media and policy narratives framed the number of people entering Europe in 2015 as a 'crises', the use of the term is contested. Instead, scholars argue that economic, social, political and environmental conditions both caused and exacerbated an ongoing issue, and that by framing the events of 2015 as a 'crisis', states and the media were able to introduce and/or reinforce 'nation-state ideologies' (Menjívar et al. 2018).

${ }^{3}$ The Schengen area is made up of 26 European states that have officially abolished passport and all other types of border control at their mutual borders although internal border controls in and between each country made be permitted on a temporary basis.

${ }^{4}$ The Dublin Regulation establishes which EU member state is responsible to assess asylum claims. The criteria for establishing responsibility run, in hierarchical order, from family considerations, to recent possession of visa or residence permit in a Member State, to whether the applicant has entered EU irregularly or regularly.
} 
amplified since 2012; at this time, the Conservative-led Government stated that they aimed to deliberately create a 'hostile environment' by denying 'illegal' immigrants access to work, housing, services and bank accounts (Kirkup and Winnett 2012). Subsequently, whilst some public servants were already responsible for enacting practices of immigration control (Humphries 2004)_-for example, checking a person's immigration documents - the 2014 and subsequent 2016 Immigration Acts extended these responsibilities to those that do not hold public office, for example, landlords and bank clerks (Crawford et al. 2016). Concurrently, fuelled by the migration crisis, there has been a continued proliferation of negative media coverage of immigration, and, coupled with increasing Islamophobia (Garner and Selod 2014), migration has also been positioned as a threat to national security. Subsequently, controlling immigration, including the free movement of people within the EU, dominated the narrative of the 2016 EU referendum Leave campaign and prevailed in subsequent Brexit negotiations between the UK and EU member states (Stone 2016).

Similarly, following the 2008 global financial crisis, Sweden implemented policies that intensified migration control and involved private actors - trade unions and employer groups-leading to an unprecedented surveillance of migrants in employment sectors (Frank 2014). Later, in 2015, as a result of the high numbers of vulnerable people entering Sweden to find refuge and seek asylum, the government argued that the welfare system risked collapse. This led to the implementation of temporary border controls, including the fencing-in of the first train station at which passengers may disembark when arriving in Sweden from Denmark (Peterson 2017). Further, the state enacted contradictory measures requiring some state actors (police, the Migration Board and some health care professionals) to surveille asylum seekers whilst requiring others (schools, NGOs and the social services in particular) to uphold their privacy rights. Parallel to this, the ruling Social Democratic Party, influenced by the far-right populist Sweden Democrat Party, initiated and has maintained ID controls and implemented legislation limiting arrivals obtaining residency permits. The intent was to send a strong message (so-called signal politics) that Sweden should not be seen by asylum seekers as an attractive destination country (Dane 2015).

Immigration control has been less prominent in Bulgarian politics, because the country's history is characterised by emigration: prior to the fall of the communist regime, in 1990, there was a large-scale outflow of Bulgarian Turks due to ethnic tensions; in 1996, emigration of ethnic Bulgarians occurred due to high inflation and political instability; and since Bulgaria joined the EU in 2007, approximately $12 \%$ of the population has emigrated (World Bank 2012). The large number of migrants travelling through Bulgaria during 2015, however, resulted in increased pressure on services and social tensions. For Kyuchukov (2015), the combined effect of the weak Bulgarian economy, and an upsurge of anti-migrant, xeno-racist narratives in the Bulgarian national media, led to fears for Bulgarian national security. This, combined with the fact that EU countries did not have harmonised asylum rules, led to Bulgarian authorities (and other countries) physically pushing vulnerable people-predominantly from the Global South — back over borders and tightening evidentiary requirements for those aiming to apply for asylum (Nancheva 2016).

In summary, then, in all three countries, during and since 2015, anti-migrant, promigration-control narratives have amplified and, to varying degrees, conflate with Islamophobic/xeno-racist opinions (Stone 2016; Nancheva 2016). Within this, as 
previously noted, a range of everyday bordering practices have been introduced (Yuval-Davis et al. 2017; Yuval-Davis et al., 2019). These narratives and the policies noted may influence public opinion (Threadgold 2009) and, for Anderson (2013), are instrumental in defining 'them' and 'us', which people are included and excluded in dominant and individual conceptions of nation state. Whilst these practices are ostensibly designed to control 'illegal' migration, the requirement, for example, to check immigration status so as to ascertain eligibility to access services, impacts on all migrant people that are checked, whatever their status (Kirkup and Winnett 2012). As such, practices can support the construction of the 'hostile environment' noted previously, whereby all immigrants - albeit within a hierarchy of migrant groups - do not 'belong' (Jones et al., 2017; Yuval-Davis et al. 2017; Yuval-Davis et al. 2019; ). Subsequently, all migrants are potentially viewed with suspicion by a range of professionals with whom they come into contact. This paper, therefore, uniquely examines whether, and in what ways, SWs from three different countries engage with these practices and are influenced by such narratives in their work with migrant family members.

\section{'Everyday Bordering' and Professional Contexts}

While social work has a professional status in Sweden, England and Bulgaria, public perceptions vary across contexts, ranging from social workers being perceived as 'never right' (England), to 'never wrong' (Sweden), to generally misunderstood or unknown (Bulgaria) (cf. Weightman and Weightman 1995, Terziev and Dimitrova 2017). Nevertheless, as noted, these street-level bureaucrats act as social agents between government policymakers and citizens (Lipsky 2010), including in matters related to immigration. Indeed, the link between migration control and welfare services has long been a feature of immigration legislation (Humphries 2004; Kremer 2007). At the time of the study, for example, EU citizens living in another EU member state only shared some welfare rights with those born in that country (Europa 2019) and in all three countries examined, legislation limits, or denies, support to failed asylum seekers (Swedish Migration Agency, n.d.; International Organisation for Migration 2016; Apostolova 2016). These examples go some way to illustrating how, in all contexts examined, street-level, everyday bordering practices regulate migrants' everyday lives, and a person's immigration status directly impacts on the services and welfare provisions to which a family is entitled, including those provided by social care practitioners.

In addition to this, the noted 'migration crisis' also unfolded in the aftermath of the 2008 global financial crash, which had further-albeit varied-impacts on the availability of social care in the countries considered. The UK government responded by implementing wide-ranging austerity measures, resulting in diminished public service provision for all (Lonergan 2015; Bywaters et al. 2017), including migrant families. The Swedish government, by contrast, stimulated the economy through infrastructure investments and fiscal measures. Incremental reductions made to government spending on social services, whilst present, were less deep-cutting than in England (Scarpa 2015). Bulgaria joined the EU in 2007, and, as a poorer country in Europe, EU financial aid and private European charitable organisations initially enabled an overall economic expansion and the development of social services (Tomev 2015). In the longer term, however, measures have not made significant improvements to Bulgaria's 
entrenched problems of poverty, and social exclusion and services remain stretched (Zahariev and Dimitrov 2010). These factors have contributed to entitlement to services in these countries being based on a range of conditions (Ibid; Walsh et al. 2018), including a person's immigration status.

In all three countries, guidance for social care professionals working with migrant families and cultural diversity is also limited and, at times, contradictory. In England and Sweden, guidance emphasises safeguarding duties, particularly in support of unaccompanied asylum-seeking minors (NBHW - National Board of Health and Welfare, 2010; DoE 2017). Further, guidelines in England note that a family's needs relating to race, culture and religion should be accommodated, but that SWs should guard against making assumptions based on race, ethnicity or cultural background if this poses a risk to children (Lamy 2003). Similarly, in Bulgaria, SWs report a low awareness of legislation and regulations to combat discrimination, particularly against ethnic minorities (Tcholakova et al. 2018). This article, therefore, examines how practitioners - as street-level bureaucrats - approach migrant family needs, in the context of reduced service provision, increasing internal bordering requirements and limited professional guidance.

\section{Methodology}

The data presented was gathered as part of an international study, which broadly aimed to examine conceptualisations of family across eight countries (Nygren et al. 2018) representing comparative approaches to family policy (Hantrais 2004). England, Sweden and Bulgaria are considered here as they are - as noted above - of comparative interest as EU member states with different welfare state systems and varied experiences of migration patterns both before, and during, the so called 'migration crises' of 2015, which coincided with the data collection period. In this paper, discussion therefore draws on data from eighteen focus groups from England, Sweden and Bulgaria. A total of eighty-three SWs took part, and sites in each country reflected a mix of urban and rural and deprived and less deprived areas.

SWs were asked to discuss a case vignette in focus groups; vignettes are effective in eliciting influential factors in decision-making processes and narratives about real-life practices (Križ and Skivenes 2013), and focus groups can reveal respondents' shared and conflicting attitudes and experiences (Linhorst 2002). At the start of this study, the international research team developed a standardised case vignette and moderator guide as a means of increasing comparative coherency across contexts (Nygren et al. 2018). This resulted in a vignette that presented SWs with a complex yet credible case with sufficient and realistic detail recognisable across all countries. The research team intentionally designed the vignette to depict a number of typical social issues (interfamilial violence, substance abuse, mental health) that occur in these countries, including one family member having a migratory background. Details of these issues and the families' circumstances were intentionally vague - including the father's country of origin - so as to elicit discussion amongst the SWs reflective of the particular social, legal and professional contexts of their practice. Whilst the vignette has limitations that should be acknowledged - for example, SW's responses to individual family members may 
be influenced by that person's gender, etc. (Nygren et al. 2018) - the use of the vignettes elicited both 'in practice' reflections related to how participants would approach the situation described in the vignette, and 'on practice' reflections related to the SWs everyday practices. The only contextual adjustments made to the vignette were to change family member's names to reflect names typical of the specific family members in the context in which the focus groups were conducted. As focus groups offer an opportunity to investigate assumptions and generalisations (Macnaghten and Myers 2007), we did not specify the father's origin as a means of allowing SWs to fill in this detail based on their own beliefs and assumptions.

The vignette was presented in three stages, in order to reveal if and how professional decision-making changed as more details about the family became available to practitioners. Researchers used standardised probing questions in order to facilitate and deepen participant discussions whilst ensuring that the data collected remained comparative. These questions, agreed by the international research team, probed respondents in all focus groups about their conceptualisations of family, and family-based social work; what actions they would take in response to the scenarios presented in the vignette; the reasons for the decisions that they would make; what interventions might be possible to provide; and what responsibilities might be borne by family members.

Synopsis of case vignette

Maria Williams and David Bey live with their three children, Beth (5), John (8) and Thomas (20). Thomas has a different father with whom he has lost contact.

Stage 1 is presented as a telephone call from Maria to a SW. Maria describes difficulties she is experiencing which include her having poor mental health and that she and David argue. She states that 'he's having so many problems with trying to live here'. There is a vague suggestion that David may be 'beating' Maria and/or the children.

Stage 2 is presented as a telephone call between a SW and a mental health worker, who expresses concerns about Maria's progress in relation to her mental health and it is revealed that Maria has problematic drinking habits. The mental health worker also reiterates that David is having problems 'living here' and states that his work 'isn't legitimate'. Maria, Beth and John also frequently stay with Maria's brother and sisterin-law.

Stage 3 is presented as a SW talking to colleagues about the case. David and Maria have separated, and the SW is concerned about the children's behaviour in school and Maria's drinking. The children are living with Maria's brother. It is noted that David's father has died and he wants to take the children to visit his mum in his country of origin.

Audio recordings of the focus groups were transcribed verbatim by a nativelanguage speaking researcher in each context. Where necessary, the researcher then translated the transcript into English, and this translation was validated by a native English-language speaker. Access to the original and English transcripts allowed researchers to analyse the full data corpus across different contexts and made it possible to check peculiarities in translation and subsequent interpretation.

The researchers applied an inductive thematic analysis (Braun and Clarke 2006). Initially, the authors read and re-read transcripts to ensure familiarity with the overall content of the data and to note any initial ideas that arose. Then, initial codes were generated for the entire data set, after which dominant codes were identified and 
systematically applied to the data, allowing themes to emerge. Via ongoing and reflexive analyses, specific characteristics of each theme were refined, and particularly exemplary extracts associated with the theme were selected.

'Everyday bordering' as an analytical frame of reference emerged from this analysis, revealing that everyday bordering practices are present, to varying degrees, in social work decision-making in England, Sweden and Bulgaria. They take both formal bureaucratic and more tacit forms, with the key themes related to social work with migrant families being: process driven everyday bordering; negotiating the internal border; and symbolic everyday bordering.

\section{Findings and Analysis}

\section{Process Driven Everyday Bordering: Migration Status and Service Provision}

'People processing' (Hasenfeld 2010) is one of the technologies used by SWs to sort the needs of service users into organisationally relevant categories, or to exclude them from services altogether. Our analysis shows that acquiring knowledge about a person's migration status - an everyday bordering practice and instrumental in people processing - can be an important feature of social work decision-making, but that reasons for this vary between countries examined. Indeed, data show that, whilst street-level bureaucratic processes clearly exist, these are constrained and influenced by the specific political and policy context. In England, SWs overtly discuss the need to establish a family's status because this can limit a person's entitlements and impact on the support they can offer to the family. As such, they express a need to understand the extent of these restrictions early in discussions:

SW: First we need to find out Maria's nationality. It clearly says that David has migrated from another country to the UK but what's Maria's nationality. We don't know about the mother's nationality and the children's nationality [...] We'd need to clarify these things. From there we can find out if they're entitled to any public funds and services or not (England)

This focus on migration status is partly due to services in England being parsed into areas of provision and entitlement to each specialist area being subject to a range of conditionalities (Walsh et al. 2018) such as only recognising biological familial bonds:

$\mathrm{R}$ : So, your work is defined by the definition in migration legislation about who is family for the purpose of family reunification.

SW: Yes, it is your spouse and your children, or just your children if maybe your spouse is deceased. They do a DNA test and that's before they would even consider issuing a visa or a passport.

R: So biological family? [agreement]

SW: If there's a spouse you have to show evidence of your relationship, which [is not possible] if you don't have a marriage certificate, which most refugees won't (England) 
As such, SWs do need to ascertain a person's migration status and, although this is unavoidable when establishing ways in which they can help, they subsequently enact government directives which limit access to services. As a result of systemic constraints and service reductions in the austerity era within which they function, SWs appear to reduce the families with whom they work to a legal migration status.

In Sweden, a person's immigration status has less of a direct influence in social work decision-making processes and, therefore, David and his family's immigration status is given little attention. There is, however, a recognition that this does impact on services families can access. They note, for example, that new legislation has ended access to Swedish language lessons for asylum seekers awaiting a decision on their case:

SW: I don't know, I think things were better before when asylum-seeking families had...or they were able to learn Swedish while their asylum applications were under review. They had more of a sense of how the community works, and the teachers did not just teach them language. They also educated them about society broadly as well. And, I think that is a big, quite a big difference [...] (Sweden)

Our data show, therefore, that whilst SWs in Sweden do understand that bordering practices impact on the availability of services for newcomers - here, asylum seekersascertaining a person's migration status does not permeate decision-making processes in the way it does in England. Whilst data does reveal narratives that are assimilationist in tone - migrants should adopt Swedish behaviours - a person's immigration status is important to social work practice because, in the context of a supposedly universal welfare system under pressure (Schierup and Ålund 2011), families with migrant backgrounds are increasingly vulnerable.

By contrast, in Bulgaria, a person's immigration status is not discussed in the context of access to, or availability of, specific services. SWs do, however, discuss how knowing a person's immigration status can affect practice decisions in other ways and they provide an example of when a family member's restrictive migration status can be used as a tool of coercion:

SW: Sometimes I use 'violence' myself to get to a good result. For instance, I tell men, in case they live in a [detention] centre, that security guards had called me to report they heard him beat his wife. "If you make me repeat this again, they will call the police and you'll be expelled from the centre" (Bulgaria)

Here, SWs engage in this everyday bordering practice, whereby they use a person's precarious migration status to obtain the cooperation of the families with whom they work and to ensure that family members behave in specific ways. As Bulgarian SWs are operating in a resource poor, overstretched service context, combining professional power with bordering practices may be a heuristic used by SWs struggling to manage large workloads (Walsh and Mason 2018).

In England, then, establishing a family member's migration status allows SWs to understand a person's entitlement to service provision, and this can be described as process driven everyday bordering. However, in a resource poor environment, this can also be seen as a way for SWs to identify which service should be responsible 
for providing support to a family or, as in Bulgaria, an everyday bordering practice that provides a moral account for professionals seeking to achieve behavioural change. This is supported by the fact that, in Sweden, where austerity has had less of an impact on service provision, SWs have an awareness of migrant entitlements (due to signal politics), but they engage less in everyday bordering since, on a broader structural level, state bordering has not intruded into as many arenas of practice.

\section{Negotiating the Internal Border: Understanding Migration Status to Establish Families' Support Needs}

Although manifestations of border control are evident in the minute of practice (Nyers 2008), SWs do not simply enact manifestations of border control in their work with migrant families. Instead, data show that SWs negotiate the complex landscape of the internal border by attempting to balance the needs of the families with whom they work, with the availability of resources and the broader demands of immigration control. Respondents in all three countries recognise that families with migrant family members are faced with additional complexities. In England, SWs recognise that migrant families are increasingly faced with bureaucratic processes and they are empathetic towards the uncertainty families can face as a result of an intentionally hostile environment:

SW: I think that David's status is a big thing because they're a couple and there's children and he's obviously been with Maria and here, now for a long time and he, just, well that must be such a stressful situation, that everyday not knowing if there's going to be a knock on the door, and for the children as well [...] [England]

SWs also indicate that they aim to support migrant families through such experiences; but to ensure that families are aware of their entitlements, they do need to understand a family's immigration situation:

SW: But he might just not know and she might just not know. Lots of people in situations like this, generally don't know what they might be entitled to [...] And, it's a very modest amount [financial support available] even when they get the whole lot, but they might just not know and so they'd need help around that (England)

Swedish SWs also recognise that a person's circumstance as a migrant can complicate an already complex family situation. They do not, however, link this to bureaucratic internal bordering processes or, as in the English account, the family feeling surveilled. Instead, in Sweden, they discuss that the father is vulnerable because he is a migranthe is in an unfamiliar environment and lacks extended family support:

SW: Well, I think he's also in a vulnerable position. He works a lot, none of his relatives live here, it's hard to get settled in this new life. He's vulnerable in his own way. He is having a hard time handling this. He's also in a relationship with 
a woman who has a problem with addiction and all that that means. And maybe he doesn't really understand what it's all about [...] (Sweden)

As such, they express empathy and recognise that the father may need help understanding the bureaucratic system in Sweden and identifying state provision available to him:

SW: And maybe he doesn't really have a good idea of the kind of support he has a right to or help that he can get from society in this new country (Sweden)

In Bulgaria, however, whilst practitioners are empathetic towards the circumstances faced by migrant families and that a family member's migration status can exclude them from aspects of Bulgarian life, this receives limited attention. Instead, the focus of discussion is on the lack of resources available to all families facing difficulties. In the following exchange, SWs feel that there are inadequate resources available to negotiate the added complexity faced by migrant families:

SW1: Things in this request are very serious. So, it's not just about one, two or three things. On top of that, there are the financial problems, there is also this refugee or migrant who, I suppose, doesn't have a status, because here in the text it is said "Experiences difficulties to live in the country" [...]

SW2: This is our everyday life. The point is that this situation requires a very quick reaction and serious resources. Resources is what we are short of [...] I guess this is how thing are, the services aren't enough to resolve a case completely. Because we, I'll say it again, are short of resources. And, if there are no services in place to unravel the problems and to tackle the essence of cases, things can hardly improve (Bulgaria)

This is compounded by the fact that, when SWs attempt to help migrant family members negotiate internal bordering processes, they are compromised by the limitations of the social system and the inefficiencies of bureaucratic, internal bordering processes. SWs express, for example, frustration at being unable to support one family with whom they work:

SW: We've been waiting for an answer from the commission for a month and a half - we wrote a letter. We have nothing to help them with (Bulgaria).

Across the countries examined, there is some shared understanding that the migration status of family members can impact on the wellbeing and support needs of families. SWs in England recognise that dealing with the bureaucracy of the UK immigration system is unsettling and can result in families feeling surveilled. Whilst Swedish and Bulgarian practitioners operate in a less 'hostile environment', they acknowledge that an insecure migration status can add to familial complexity. Swedish and English SWs recognise that they need to establish a family's migration status in order to develop a support plan that attempts to meet the family's needs. In doing so, they negotiate aspects of everyday bordering with the aim of assisting families new to complex 
bureaucracies that they do not understand. As such, they are complicit in bringing bordering practices into the everyday lives of migrant families, albeit for reasons that are beyond their control and, often, well intentioned. In Bulgaria, however, where service provision is the most restricted, negotiating the difficulties experienced by families with a migratory background is not prioritised. Consequently, as there are very few opportunities for SWs to exercise professional discretion by enabling migrant families to access support, Bulgarian SWs may be understood to inadvertently enact practices of everyday bordering.

\section{Symbolic Everyday Bordering: Racialised Masculinities and the Resultant 'Othering' of Migrants}

Uniquely, our analysis reveals that SWs in all three countries engage in subtle racialised practices that intersect with everyday bordering practices; in an atmosphere of suspicion towards migrants, those assumed to be culturally different are, to varying degrees, othered (Khosravi 2010: 98). In England, for example, when discussing David's country and culture of origin, SWs assume that if he is not of Christian, European heritage, he is more likely to engage in and accept family violence. The implied 'beatings' are attributed to cultural difference in terms of physical chastisement of children and/or intimate partner violence, and a direct link is made to Asian men and Sharia law:

SW: [...] Is he from a different nationality? Is there a different, culture, you know, what he thinks being a good parent is, that you can beat your kids? [...] I've had cases, maybe not in this role, where there's been cultural issues like this. In some areas, where there's been Asian males, and lots of DV [domestic violence], and a lot of that stemmed from, what's that other law called, Sharia law, and the differences of expectations of family roles and extended family roles and the what's expected of the children, so yeah, we would see things like this. Because, what's acceptable is sometimes illegal kind of thing (England)

More broadly, English SWs also make implicit assumptions that non-normative, culturally located family practices are abusive and/or illegal (Welbourne and Dixon 2015). Although the specific culture is not stated in the vignette, SWs attribute the family practices described to a particular group, and, subsequently, they position migrant families from this group as being different or other.

In the Swedish data, assumptions are also made about the ways in which cultural norms impact on parenting, further revealing homogenised views of families that are not of Christian, European heritage, particularly in relation to 'honour'-based violence. This term refers to any form of violence perpetrated against women within a framework of patriarchal family structures and is primarily associated with Arab, Middle Eastern and African families (Gill and Brah 2013). SWs discuss how migrant parents may feel the need to control their children because they are in an unfamiliar and unsettling situation 'and that might be where things like honour [based violence] come in' (Sweden). Practitioners also note that it is problematic when parents of unaccompanied asylum-seeking minors arrive in Sweden, because 
their cultural norms are positioned as being incompatible with normative ideas on becoming Swedish:

SW1: Maybe the child arrived here at the age of 14, let's say, and we have worked hard to integrate them into Swedish society and a Swedish way of thinking [...] after three years they have been quite successful with it - then the parents arrive, and they are supposed to go back to step 1.

SW2: Or they [parents] do not understand this freedom, identity development, adolescence and liberation [...] but when they bring dishonour onto the family, that is the most difficult (Sweden).

SWs in Bulgaria also make generalised assumptions about the use of violence as a parenting practice prevalent amongst 'refugees' with whom they work:

SW: As to violence, if we come back to the question of violence and beating as a method of bringing up children or of dealing with children with problems, or dealing with some other issues, I think it is widely practiced among refugees (Bulgaria)

Whilst these SWs do make assumptions about the father being a refugee - and thus, in 2015, presumed to be from the Global South - and link this to family violence, they also assert that the use of violence can occur because of the precarity of refugee life and acknowledge that 'beating children' is also present in Bulgarian families:

SW: And this is purely cultural, because it somehow isn't judged. It isn't considered a forbidden thing, a thing which is not allowed and is better to avoid. To some extent this applies to Bulgarian families too, although we usually claim we are against beating children. Also, when it particularly comes to families of refugees and resorting to violence in the family, most of the time it is the result of what they went through. Like the difficult journey, the things they lost, the current hardships, etc. (Bulgaria)

SWs in all three countries examined, therefore, interpret the 'use of violence' as being culturally located, although this is less so in Bulgaria. What becomes known as 'race' is constructed out of the 'particular ways in which people are classified and seen' (Murji and Solomos, 2005: 8). As such, this can result in migrant cultures and families affected being viewed as a homogenous group that are 'backward and unchanging' rather than families characterised by heterogeneity (Gill and Brah 2013:73).

Further, in all three countries, as discussion continues, David's desire to take the children to visit their grandmother in another country is met with suspicion because of the father's cultural origins:

SW: You'd want to, really want to understand, because potentially in terms of identity this could be a really positive trip for the children, but actually this could be an entry into FGM [female genital mutilation] for the girl. There's a whole lot of complexity in that. It could be, and actually, we are not taking you back (England) 
The risk of the father leaving the country with his children and not coming back is also discussed in Swedish focus groups and notably where the father is from also influences the level of risk SWs assess the trip to pose:

SW: For me it rings alarm bells that he has thought about taking them with him for a visit. The risk. It feels like they could end up staying there. That's my main thought [...] so it feels 'so so' that he wants to go away for a visit to show where he grew up. It sets off alarm bells to me (Sweden)

In England, the level of suspicion and assessed risk is such that SWs explicitly discuss the father's intentions and that this may warrant the imposition of a statutory 'prohibitive steps order' to stop him taking the children out of the country. Bulgarian SWs, however, assess the situation differently. Rather than making racialised assumptions that David's trip abroad may be 'risky', their discussions are influenced by their own country's emigration history resulting in many families, not just migrant families, having family members living in another country:

SW1: As for him, as soon as his mother gets ill, he hurries to go back to his country $[\ldots]$ Is he able to take responsibility fully and autonomously as a father, or would he rather turn back to the place that he has never completely detached from? So much work can be done with these children so that they accept the family they come from for what it is, and towards figuring out what would be the best thing to do for themselves.

SW2: Because there are a lot of children like that. And it is not only children of migrants who are in such a situation. There are too many Bulgarian families like this one as well. In a very similar condition (Bulgaria)

In all the countries examined, then, SWs make racialized assumptions that intersect with practices of everyday bordering and position migrant men that are not of Christian, European heritage, as 'outsiders' that may present a threat to their family's wellbeing. In Sweden and England, this extends to assumptions that taking the children to visit their transnational family is risky (Abbas 2005; Britton 2019). As such, SWs can be seen to inadvertently engage in a symbolic form of everyday bordering that positions migrant families as other. Bulgarian SWs do, however, clearly state that the potential violence, and the desire to return home to their family in another country 'applies to Bulgarian families, too'. In a resource poor context, where narratives of immigration control are not prevalent, the shared experience of families living geographically separate seems to prevail; rather than engage in bordering practices that position David as other, SWs draw parallels between the challenges of working with both migrant and Bulgarian families.

\section{Discussion}

Overall, this paper develops the concept of everyday bordering (Yuval-Davis et al. 2017; Yuval-Davis et al. 2019) by uniquely showing that internal bordering practices 
are evident in the comparative professional space of SWs in England, Sweden and Bulgaria; examples provided in the findings and analysis section show that practitioners, to varying degrees, do act as street level bureaucrats (Lipsky 2010). In addition, contextual and other intersecting factors influence the ways, and extent to which, everyday bordering permeates social work practice and shapes migrant families' experiences of social care. These factors include: prevalent policy and media narratives; if the country is a receiving or transit country for immigrants; the reality of pressures on local social care services in 2015; and the broader social care context. Overall, our data show that everyday bordering, and political and policy contexts, affect social work practice in three ways: process driven everyday bordering; negotiating the internal border; and symbolic everyday bordering.

Process driven everyday bordering occurs when a person's immigration status influences the support practitioners offer to migrant family members and then intersects with the availability of resource in the service context. In England, where immigration policy is intentionally 'hostile' (Kirkup and Winnett 2012; Jones et al. 2017), and austerity measures have resulted in much reduced service provision (Walsh et al. 2018), SWs engage in a seemingly clinical dissection of a person's immigration status. Whilst a SW's ability to refer and signpost family members to limited services $i s$ heavily influenced by complex conditions, some related to their migration status, by dwelling on this, English SWs are complicit in the enactment of bureaucratic bordering practices. The impact of limited resources on social work practice with migrant families is most stark in the Bulgarian context. Here, where measures to control immigration are directly related to the crisis, it appears to be the pressures experienced within the broader social care system that result in practices that can be described as everyday bordering; knowledge of a person's precarious status can be used as a tool of coercion to accelerate behavioural change. By contrast, in Sweden - the country of the three to receive by far the most asylum applications in the 2015 period - signal politics has presented immigration as a problem to be controlled, but austerity has had significantly less impact on service provision (Dane 2015). Whilst SWs are aware of reduced migrant entitlements in the era of signal politics, they do not employ everyday bordering in the ways described in England or Bulgaria. This is perhaps because they are not faced with the systemic pressure to identify if they should provide support and/or to find time efficient ways of managing caseloads.

We also show, however, that SWs do not simply enact government policy in their work with migrant families. Instead, we contribute to knowledge of social work practice by showing that, in all contexts, they engage in transgressive processes and negotiate the internal borders described; they attempt to balance the needs of the families with whom they work, with the availability of resources and the broader demands of immigration control. Across the countries examined, there is, then, some shared understanding that being a migrant can impact on the wellbeing and support needs of families. SWs in England, for example, recognise that dealing with immigration system bureaucracy is unsettling and can result in families, in a 'hostile environment', feeling surveilled. Whilst these policy and media narratives are less prevalent in Sweden and Bulgarian, SWs in these contexts also understand that an insecure migration status adds to familial complexity. In Sweden and England, SWs, thereby, attempt to help migrant families understand their circumstance and develop a support plan that meets their needs and identifies support to which they are entitled. In doing so, SWs 
negotiate aspects of everyday bordering - they exercise professional discretion - so as to support families new to complex bureaucracies that they do not understand. In Bulgaria, however, in the context of seriously restricted service provision and national policies of securing external borders, identifying entitlement to support and negotiating strategies to minimise the impact of everyday bordering on migrant families is not prioritised by SWs. Opportunities to exercise professional discretion are thus limited leaving SWs to engage in practices of everyday bordering however inadvertent these may be.

We also develop the concept of everyday bordering by revealing that, in all three countries, related practices extend beyond SWs enacting bureaucratic requirements. Instead, they can encompass what we refer to as symbolic everyday bordering, tacit assumptions that contribute to the othering of migrant families. SWs in all three countries assume that because David is a migrant, he is not of Christian, European heritage, and they make racialised assumptions that this is likely to influence what he sees to be appropriate relational behaviours (Britton 2019). Here, because migrants entering Europe in 2015 were predominantly Asian, African and Middle Eastern, compounded by increasing xeno-racism (Stone 2016; Nancheva 2016), participants in all countries assume David must be from these areas, and abusive behaviours are positioned as culturally located. Where guidance on working with migrant families and cultural difference is limited, absent and/or contradictory, racialised everyday bordering practices occur to varying degrees and contribute to creating the sense of 'them' and 'us', and who does and does not belong (Anderson 2013; Yuval-Davis et al. 2017; Yuval-Davis et al. 2019).

\section{Conclusion}

Overall, this comparative study reveals the ubiquitous nature of internal bordering practices in contemporary Europe and shows that SWs, as street-level bureaucrats (Lipsky 2010), do enact bordering practices in their work. We also show that the policy, political and service context within which people operate is highly influential and, when time and resource are scarce, everyday bordering can be used as a heuristic in social work decision-making (Walsh and Mason, 2018). Importantly, we also contribute by highlighting that SWs in all contexts recognise the difficulties faced by migrant families and do attempt to negotiate the complex terrain of immigration legislation and minimise some of the impacts of everyday bordering. However, it remains that in enacting these practices, SWs, to varying degrees, contribute to the multiple bureaucratic and symbolic ways in which immigration is controlled and surveilled (Brambilla et al. 2015; Jones et al. 2017). Recognising that everyday bordering is a further encroachment on professional discretion, and the ways in which migrant families experience social care support, is an important step toward resistance and returning to principles of social justice. However, efforts toward improving the wellbeing of migrants require more than just a recommitment to these principles by SWs. Whilst it is recommended that the findings presented here inform future practice guidance for professional supporting families that migrate, this alone will not change the professional context within which social workers operate. Instead, further research should consider ways in which everyday bordering affects the lived realities of migrant 
families engaging with social care provision - their outcomes in each context - and how they, and practitioners, might challenge the impact of bordering on their lives and practices.

Funding The research upon which this paper is based was gathered as part of the Family Complexity and Social Work (FACSK) project. This was funded by New Opportunities for Research Agency Cooperation in Europe (NORFACE), specifically, the Welfare State Futures (WFS) funding stream.

Open Access This article is licensed under a Creative Commons Attribution 4.0 International License, which permits use, sharing, adaptation, distribution and reproduction in any medium or format, as long as you give appropriate credit to the original author(s) and the source, provide a link to the Creative Commons licence, and indicate if changes were made. The images or other third party material in this article are included in the article's Creative Commons licence, unless indicated otherwise in a credit line to the material. If material is not included in the article's Creative Commons licence and your intended use is not permitted by statutory regulation or exceeds the permitted use, you will need to obtain permission directly from the copyright holder. To view a copy of this licence, visit http://creativecommons.org/licenses/by/4.0/.

\section{References}

Anderson, B. (2013). Us and them: The dangerous politics of immigration control. Oxford University Press. Anthias, F. (2021). Translocational belongings: Intersectional dilemmas and social inequalities. Routledge. Apostolova, R. (2016). The Real Appearance of the Economic/Political Binary: Claiming Asylum in Bulgaria. Intersections, 2(4), 33-50.

Berry M., Garcia-Blanco, I. \& Moore K. (2015). Press coverage of the refugee and migrant crisis in the EU: A content analysis of five European countries. UNHCR.

Björngren Cuadra, C., \& Staaf, A. (2014). "Public social services" encounters with irregular migrants in Sweden: Amid values of social work and control of migration. European Journal of Social Work, 17(1), 88-103.

Brambilla, C., Laine, J., \& Gianluca, B. (2015). Borderscaping: Imaginations and practices of border making. Routledge.

Braun, V., \& Clarke, V. (2006). Using thematic analysis in psychology. Qualitative Research in Psychology, 3, 77-101.

Briscman, L., \& Dean, Y. (2016). Social workers without borders: Voices for justice. Ethics and Social Welfare, $10(2), 185-187$.

Britton, J. (2019). Muslim men, racialised masculinities and personal life. Sociology, 53(1), 36-51.

Bywaters, P., Brady, G., Bunting, L., Daniel, B., Featherstone, B., Jones, C., Morris, K., Scourfield, J., Sparks, T., \& Webb, C. (2017). Inequalities in English child protection practice under austerity: a universal challenge? Child and Family Social Work, 23(1), 53-61.

Cassidy, K., Yuval-Davis, N., \& Wemyss, G. (2018). Debordering and everyday (re)bordering in and of Dover: Post-borderland borderscapes. Political Geography, 66, 171-179.

Cemlyn, S. J., \& Nye, M. (2012). Asylum seeking young people: Social work value conflicts in negotiating age assessment in the UK. International Social Work, 55(5), 675-688.

Chantler, K. (2012). Gender, asylum seekers and mental distress: Challenges for mental health social workers. British Journal of Social Work, 42(2), 318-334.

Cox, P., \& Geisen, T. (2014). Migration perspectives in social work research: Local, national and international contexts. British Journal of Social Work, 44, i157-i173.

Crawford, J., Leahy, S., \& McKee, K. (2016). The Immigration Act and the "Right to rent": exploring governing tensions within and beyond the state. People, Policy and Place, 10(2), 114-125.

Dane, L. (2015). The story of when Sweden went from TUT to PUT as the main rule for protection - or: the art of now going back in history...[Blog post]. https://ouisedane.wordpress.com/2015/10/17/historien-omnar-sverige-gick-fran-tut-till-put-som-huvudregel-for-skyddsbehovande-eller-konsten-att-ga-bakat-ihistorien/ accessed 28 april 2020.

DoE (2017). Safeguarding Strategy. Unaccompanied asylum seeking and refugee children. <https://assets. publishing.service.gov.uk/government/uploads/system/uploads/attachment_data/file/656425/UASC_ Safeguarding_Strategy_2017.pdf> accessed 19 Dec 2018. 
Europa (2019). What are your EU citizenshiprRights <https://ec.europa.eu/unitedkingdom/services/yourrights_en> accessed 18 Feb 2019.

Eurostat (2016). Eurostat News Release. <https://ec.europa.eu/eurostat/documents/2995521/7203832/304032016-AP-EN.pdf/790eba01-381c-4163-bcd2-a54959b99ed6> accessed 22 Nov 2018

Fell, B., \& Fell, P. (2014). Welfare across borders: Social work process with adult asylum seekers. British Journal of Social Work, 44(5), 1322-1359.

Frank, D. (2014). Changes in migration control during the neoliberal era: Surveillance and border control in Swedish labour immigration policy. Journal of Political Power, 7(3), 1-20.

Garner, S., \& Selod, S. (2014). The racialization of Muslims: Empirical studies of islamophobia. Current Sociology, 41(1), 9-19.

Gill. K. \& Brah, A. (2013). Interrogating cultural narratives about 'honour' - based violence. European Journal of Women's Studies, 21(1).

Greenslade, R. (2005) Seeking Scapegoats: The coverage of asylum in the UK press, Asylum and migration. Working paper 5 of the asylum and migration series. London: Institute of Public Policy Research.

Hantrais, L. (2004). Family policy matters. Responding to family change in Europe. The Policy Press.

Hasenfeld, Y. (Ed.). (2010). Human Services as Complex Organizations. Sage.

Humphries, B. (2004). An unacceptable role for social workers: Implementing immigration policy. British Journal of Social Work, 34(11), 93-107.

JCWI. (2015). "No passport equals no home": An independent evaluation of the "right to rent" scheme. Joint Council for the Welfare of Immigrants.

Jenkins, M. (2014). On the effects and implications of UK Border Agency involvement in higher education. The Geographical Journal, 180(3), 265-270.

Jones, H., Gunaratnam, Y., Bhattacharyya, G., Davies, W., Dhaliwal, S., Forkert, K., Jackson, E., \& Saltus, R. (2017). The Politics of Immigration Controversies. Manchester University Press.

Khosravi, S. (2010). 'Illegal' traveller: an auto-ethnography of borders. Palgrave Macmillan.

Kirkup, J. and Winnett, R. (2012). Theresa may interview: 'We're going to give illegal migrants a really hostile reception'. The Telegraph.

Kremer, M. (2007). How welfare states care: culture, gender and parenting in Europe. Amasterdam University Press.

Križ, K., \& Skivenes, M. (2013). Systemic differences in views on risk: A comparative case vignette study of risk assessment in England, Norway and the United States (California). Children and Youth Services Review, 35(11), 1862-1870.

Kyuchukov, L. (2015). Impact of the refugee crisis on Bulgarian society and politics: fears but no hatred. Friedrich Ebert Foundation.

Lamy, D. (2003). The Victoria Climbiée Enquiry. HMSO.

Linhorst, D. (2002). A review of the use and potential of focus groups in social work research. Qualitative Social Work, 1(1), 208-228.

Lipsky, M. (2010). Street-level bureaucracy: The dilemmas of the individual in public service (30th edition). Russell Sage Foundation.

Lonergan, G. (2015). Migrant women and social reproduction under austerity. Feminist Review, 109, $124-145$.

Macnaghten, P., \& Myers, G. (2007). Focus Groups. In C. Shale, D. Silverman, J. Gubrium, \& G. Gobo (Eds.), Qualitative Research Practice. Sage.

Menjívar, C., Ruiz, M., \& Ness, I. (Eds.). (2018). The Oxford Handbook of Migration Crises. Oxford University Press.

Molander, A. (2016). Discretion in the welfare state : Social rights and professional judgment. Routledge.

Mulvey, G. (2010) When policy creates politics: The problematizing of immigration and the consequences for refugee integration in the UK, Oxford Journals Online. Available online : http://jrs.oxfordjournals.org/ content/early/2010/11/17/jrs.feq045

Murji, K., \& Solomos, J. (2005). Racialization: Studies in theory and practice. Oxford University Press.

Nancheva, N. (2016). Bulgaria's response to refugee migration: Institutionalizing the boundary of exclusion. Journal of Refugee Studies, 29(4), 549-567.

NBHW - National Board of Health and Welfare (2010). Interkulturellt socialt arbete. <https://www. socialstyrelsen.se/publikationer2010/2010-6-9> accessed 22 Feb 2019.

Nyers, P. (2008). No one Is illegal between city and nation. In G. Nielsen (Ed.), Acts of Citizenship. Zed Books.

Nygren, K. Walsh, J., Ellingsen, I.T. \& Christie, A. (2018). What about the fathers? The presence and absence of the father in social work practice in England, Ireland, Norway and Sweden. Child \& Family Social Work, 24(1), 148-155.

Nygren, L., White, S., \& Ellingsen, I. (2018). Investigating welfare regime typologies: Paradoxes, pitfalls and potentialities in comparative social work research. Social. Policy and Society, 17(4), 665-677. 
Ozdemir, Z., \& Ayata, A. (2018). Dynamics of exclusion and everyday bordering through Schengan visas. Political Geography, 66, 180-188.

Parker, N., \& Adler-Nissen, R. (2012). Picking and choosing the 'sovereign' border: A theory of changing state bordering practices. Geopolitics, 17(4), 773-796.

Peterson, A. (2017). Humanitarian border workers in confrontation with the Swedish state's border making practices: "The death of the most generous country on Earth". Journal of Borderlands Studies, 1-17.

Prottas, J. M. (1978). The Power of the Street-Level Bureaucrat in Public Service Bureaucracies. Urban affairs review, 13(3), 285-312.

Scarpa, S. (2015). The Swedish model during the international financial crisis: Institutional resilience or structural change? In S. Romano \& G. Punziano (Eds.), The European social model adrift: Europe, social cohesion and the economic crisis (pp. 107-125). Routledge.

Schierup, C.-U., \& Ålund, A. (2011). The end of Swedish citizenship? Neoliberalism and the politics of exclusion. Race and Class, 53(1), 45-64.

Shier, M. L., Engstrom, S., \& Graham, J. R. (2011). International migration and social work: A review of the literature. Journal of Immigrant and Refugee Studies, 9(1), 38-56.

Statista (2018) Net Migration in Selected European Countries. Available at: https:/www.statista.com/ statistics/686124/net-migration-selected-european-countries/

Stone, J. (2016). Politicians' anti-immigrant rhetoric fuelled post-Brexit hate crime spike. The Independent, $26^{\text {th }}$ August.

Sundqvist, J., Hansson, J., Ghazinour, M., Ögren, K., \& Padyab, M. (2015). Unaccompanied asylum-seeking refugee children's forced repatriation: Social workers' and police officers' health and job characteristics. Global Journal of Health Science, 7(6), 449-453.

Swedish Migration Agency (n.d.). If your application is refused. <https://www.migrationsverket.se/English/ Private-individuals/Protection-and-asylum-in-Sweden/When-you-have-received-a-decision-on-yourasylum-application/If-your-application-is-refused/If-your-application-for-asylum-is-refused.html> accessed 19 Dec 2018.

Tcholakova, M., Sotirova, V., \& Tzvetanova, Y. (2018). Reflections on discrimination and oppression in contemporary social work practice in Bulgaria. European Journal of Social Work, 21(5), 665-683.

Tervanon, M., \& Enache, A. (2017). Coping with everyday bordering: Roma migrants and gatekeepers in Helsinki. Ethnic and Racial Studies, 40(7), 1114-1131.

Tervonen, M., Pellander, S., \& Yuval-Davis, N. (2018). Everyday bordering in the Nordic Countries. Nordic Journal of Migration Research, 8(3), 139-142.

Terziev, A. \& Dimitrova, P. (2017). Research, Identification and Monitoring of the Needs of Occupational Training and Social Activities Experts. American Journal of Education Blog.

Threadgold, T. (2009). The media and migration in the United Kingdom, 1999 - 2009 Migration Policy Institute.

Tomev, L. (2015). The Economic and social situation in Bulgaria. The European Economic and Social Committee.

Walsh, J. \& Mason W. (2018). Walking the Walk: Changing Familial Forms, Government Policy and Everyday Social Work Practice in England. Social Policy and Society, 17(4), 603-618.

Walsh, J., White, S., Morris, K \& Doherty, P. (2018). How do you solve a problem like Maria? Family complexity and institutional complications in UK social work. European Journal of Social Work, 22(6), 1050-1061.

Weightman, K. \& Weightman, A. (1995). "Never right, never wrong": child welfare and social work in England and Sweden. Scandinavian Journal of Social Welfare, 4(2), 75-84.

Welbourne, P., \& Dixon, J. (2015). Child protection and welfare: cultures, policies and practices. European Journal of Social Work, 19(6), 827-840.

Yuval-Davis, N., Wemyss, G., \& Cassidy, K. (2017). Everyday bordering, belonging and reorientation of British immigration legislation. Sociology, 52(2), 1-17.

Yuval-Davis, N., Wemyss, G and Cassidy, K. (2019) Polity.

Zahariev, B., \& Dimitrov, D. (2010). Evaluation report 2010 Bulgaria: Poverty during crisis. In Evaluating the impact of the economic crisis on poverty and social exclusion in Bulgaria. UNICEF \& the Expert Analysis Group.

Publisher's Note Springer Nature remains neutral with regard to jurisdictional claims in published maps and institutional affiliations. 